Adapting to a United Kingdom Undergraduate Engineering Pedagogical Approach While Teaching at a Sino-Foreign Joint Educational Programme

Dr. Kathleen Meehan, University of Glasgow 


\title{
Adapting to a United Kingdom Undergraduate Engineering Pedagogical Approach While Teaching at a Sino-Foreign Joint Educational Programme
}

\begin{abstract}
An American's view of the differences and similarities between the United Kingdom and Chinese approaches to undergraduate engineering education with an acknowledgement of the approaches used in the United States will be presented. This view is formed from her experiences at the University of Glasgow (UoG), the joint educational programme (JEP) between the University of Glasgow and the University of Electronic Science and Technology of China (UESTC), and at three institutions of higher learning (IHLs) in the United States. Comparisons include the curricula, student and instructor expectations, instructional techniques, assessment of learning, programme accreditation and quality assurance, privacy of information, and parents' rights and engagement at UoG, UESTC, and the three US IHLS at which the author has taught. Observations of the author's experience teaching at the UoG-UESTC JEP and as programme director are made, which may be of use to academics who may be interested in a similar position at a Sino-foreign joint programme or at university in the United Kingdom and for those interested in developing a joint educational programme between institutions that are geographically and philosophically apart.
\end{abstract}

\section{Introduction}

There were over 1900 joint educational programmes (JEPs), collaborations between Chinese institutions and foreign institutions as of $2013^{1}$. These JEPs included a wide range of educational activities - everything from nursery schools to institutes of higher learning (IHLs) that only offer graduate degrees. Of these JEPs, only 17 involved an institute of higher learning in $2010^{2}$, though this number has increased significantly and is expected to continue to grow ${ }^{3}$.

In September 2013, the University of Glasgow (UoG) and the University of Electronic Science and Technology of China (UESTC) opened the doors to the UoG-UESTC Joint School with 144 students enrolled in a dual degree programme in Electronic and Electrical Engineering (EEE) ${ }^{4}$. The courses in the UoG-UESTC JEP are taught roughly 50:50 by UoG and UESTC staff. The courses that contribute to the UoG EEE degree are taught in English, no matter if course instructor is a UoG or UESTC staff member. While UoG staff teach more of the Year 3 and Year 4 courses, there was a conscious decision to have UoG staff teach three courses in each of the first two years. This allows the students to engage with UoG staff as soon as they begin their academic careers and the UoG staff can introduce its pedagogical approach to the students as well as to the UESTC staff involved in the Joint School. It has also meant that UoG teaching and administration staff have been actively involved in the day-to-day evolution of the Joint School from the day the Joint School opened. With the enrollment of the second cohort of students, the Joint School has a total of 379 students and 24 academic and administrative staff members -21 employed by UESTC and 3 employed by UoG.

Advertisements of the UoG staff positions to support the UoG-UESTC Joint School were posted widely with applications received from candidates around the world. The three staff who were 
hired had experience in teaching at institutions in China, New Zealand, Canada, and the United States (US). This has presented an interesting issue as the UoG staff have to learn the pedagogical approaches as well as the university policies employed at UoG, the UoG 'ethos', at the same time that they were charged with introducing the UoG 'ethos' to the UoG-UESTC student. While there are some differences in instructional approaches used in the five different countries, the differences between underlying pedagogical philosophies are significant. Furthermore, the role of the educational institution and its staff in the students' extracurricular activities differs considerable.

The author, an American who has worked full-time for 16 years at three different universities in the United State, will provide her views of the differences and similarities between American, United Kingdom (UK), and Chinese approaches to education based upon her experiences at UoG, UoG-UESTC, and the IHLs in the United States. In the paper, it is presumed that the reader is familiar with the higher educational system in the United States so explanations of the US system are not provided. The most of the titles for sections of the paper are composed of terminology used at the University of Glasgow, next in the United States, and then at the University of Electronic Science and Technology of China. Mathematical symbols are used between each phrase to indicate the relative similarity of each of the terms. English spellings of words are used when issues concerning the University of Glasgow are described while American spellings are used in the discussions about the UESTC educational system. American terms for terminology used at the University of Glasgow are placed in parenthesis immediately after the UoG term.

\section{Programme Specification = Curriculum = Educational Plan}

\section{(a) University of Glasgow}

The Electronics and Electrical Engineering, abbreviated as EEE, undergraduate engineering degree offered by UoG, as is typical for Scottish universities, is four-year programme of study whereas similar degrees offered in England are usually three-year courses of study. However, the length of study for students who complete a Master's degree in Scotland and England are about the same, five years in total for the undergraduate and Master's degree combined.

The UoG EEE programme specification ${ }^{5}$ is a document that describes the aims of the programme, the intended learning outcomes achieved by graduation, a summary of the major techniques used to assess students' learning, a description of the learning and teaching approaches that students and academic staff are expected to employ, and the list of required and elective courses per year as well as links to quality assurance and accreditation procedures. In essence, the document contains much of the information that institutions of higher learning in the United States are expected to make publically available for their equivalent degree programs where the programme aims are equivalent to program educational objectives (equivalent to $A B E T$ Criterion 2 ) and the intended learning outcomes are similar to student outcomes (equivalent to ABET Criterion 3$)^{6}$.

There are several major differences in the courses required for graduation at the University of Glasgow and other universities in the United Kingdom as compared to in the United States. First, 
there are no required liberal arts courses. Lectures may touch on issues related to proper formats and writing styles for laboratory report and technical paper, examples of such documents may be distributed to students in the course notes, and some support is provided to UoG students by the university's English Language Centre. Secondly, there are no science courses explicitly required in the EEE programme, though there are biology courses required in the Biomedical Engineering programme and computer science courses in the Electronics and Software Engineering degree programme. Instead, many of the engineering courses include lectures on topics from the physical sciences so that students learn concepts from physics and chemistry as applied in specific engineering fields.

There are, of course, significant similarities between degree programmes offered by the University of Glasgow and those offered by the three institutions that the author is most familiar with in the United States. In EEE, students are exposed to foundation courses in the discipline: circuits, $\mathrm{C}$ programming, digital logic, and microprocessors in Years 1 and 2 and discipline-specific courses in communications, power systems, microelectronics, embedded systems, fields, and controls in Year 3. In Year 4, students may specialise within a particular EEE disciplines through their selection of elective courses and their choice of topic for the Individual Project, a required capstone design course. There is a heavy emphasis on hands-on learning with laboratories and projects integrated into almost all of the engineering courses as well as two stand-alone courses that involve team design projects. There are required mathematics, or maths, courses in the EEE programme during the initial two years, although these courses have been designed to provide students with examples of engineering applications of mathematics in the lectures as well as on the exams. In addition, there are both required and elective courses on professional practice that include topics from engineering economics, project management, and professional ethics.

The programme specification, as well as any revisions to the original specification, must be approved by the School of Engineering Learning and Teaching Committee (curriculum committee), then the College Teaching and Learning Committee before the final approval by the University Senate. All course specifications (syllabi) for the courses identified in the programme specification must be either already approved or approved at the same time as approval of the programme specification is sought.

\section{(b) University of Electronic Science and Technology of China}

In contrast, the educational plan ${ }^{7}$ for the Electronic and Electrical Engineering undergraduate degree at the University of Electronic Science and Technology of China (UESTC) follows the format used in the United States. It is a four-year plan with required courses in the humanities along with the courses in electronics and electrical engineering that build from the foundational courses to discipline-specific to technical electives. The Teaching Office at UESTC has similar authority as the UoG University Senate and approves educational plans.

Students can choose to specialize through their choice of technical electives in Year 2, earlier in their studies as compared to the programs in the US with which the author is most familiar. The required hands-on experience in Years 1-3 is gained through companion laboratory courses; the companion lab course is typically taught by a different instructor than the faculty member who is teaching the lecture course. In addition, projects may be assigned in lecture courses that do not have a companion lab course. In Year 4, students are required to enroll in a capstone design 
course, which is an individual rather than a team project. The laboratory courses and projects in the degree program are not as numerous as the total in the UoG EEE programme, but are equivalent in number to that in the US EE programs in which the author has taught.

\section{Self-Guided Learning $\subset$ Student-Centered Learning $\supset$ Teacher-Centered Instruction}

\section{(a) University of Glasgow}

The contents of each course is described in the course specification (syllabus), which lists the intended learning outcomes, the number of hours that the course instructor and each student should devote to the separate course components [lectures, tutorials (recitation sessions), laboratory experiments and/or projects, homework assignments, quizzes, class exams, and final exam], the summative assessments and their weighted contributions to the calculation of the final grade, opportunities for resits, and the textbook and other supplemental learning materials.

A course convener (course supervisor) usually provides all of the lecture notes, supplemental materials, and laboratory exercises to the staff member who has been assigned as the course instructor for the current semester. This insures that the students receive the same guidance on the course topics that should be learned and students develop the same practical skills in each semester that the course is offered. The course instructor may select which notes should be covered in each lecture period, as it is common that not all of the course notes are presented to students during the lectures but are available to the students to review on Moodle 2, the virtual learning environment adopted by the University of Glasgow ${ }^{8}$. These notes may summarise or expand upon material collected from one or more textbooks. In the EEE programme, it is rare that a course will have a required textbook, but a list of suggested texts that include one or all of the topics that students are expected to learn by the end of the semester is usually provided to students to support their learning.

The course instructor is expected to be present during the laboratory sessions in courses that contain a practical skills component along with support staff, the postgraduates (graduate students) and/or electronic shop technicians, so that the instructor can answer questions about the lab exercises as well as one-on-one or one-on-few discussions about specific technical concepts from the lectures and readings. Course instructors may also hold office hours.

The UK educational system encourages self-guided learning by students. Course lectures are designed to provide students with some guidance on the topics in a specific area of study. As a result, 20 hours on average are spent on lectures per course per semester, about $50 \%$ of the hours of lecture normally given per course in the US. On the other hand, the course laboratory exercises are very structured, cookbook-ish, as they are typically designed to build practical skills in circuit simulation, construction, and measurement and not to stimulate creativity and innovation of design. The labs are generally 3 hours in length and designed so that most students complete the simulations and measurements during the lab session. Open-ended design projects are introduced in the team project courses in Years 2 and 3. Students are expected to demonstrate the integration of practical skills, conceptual learning, and creativity of design in the Individual Projects in Year 4. As a result, attendance during lectures is not required. Attendance 
is mandatory at all laboratory sessions; failure to attend will result in credit being withheld at the end of the semester.

Tutorial sessions are opportunities for students who have questions about concepts, possibly identified while solving problems, which may or may not be graded, to have these questions addressed by the course instructor. Revision is a period of time, at least one week in length, when no lectures or laboratories are held so that students can prepare for the final exam. Resits are opportunities for students who fail to pass a course to improve their grades on allowed assessed components of the course including the final exam. The resit of all allowed components of a course must be completed before the Progress Committee meeting is held. The purpose of the Progress Committee will be described in Section VI.

Perceived changes in the preparation and expectations of students entering the university have led some staff to advocate a move towards the US-model of instruction in Year 1 courses. Instruction in the US has been evolving towards student-centred instruction, but it is the guidance on the topics that students should study and feedback on the students' learning, provided by regularly assessed homework assignments and class exams in US-taught courses that some staff are proposing to adopt to allow students to more gradually transition to self-directed learning.

\section{(b) University of Electronic Science and Technology of China}

The contents of a course are provided in the course syllabus, which can be a short description or a detailed listing of the topics of study. Also included in the syllabus are the types of summative assessments and their weighted contributions toward the final grade and information on the required textbook and supplemental learning materials.

The Chinese educational system is teacher-centric with strong guidance provided to students on the material that should be learned. Usually, the course instructor presents all of the concepts and applications that must be learned in detail. Hence, the number of hours devoted to lectures in a particular course per semester is greater than the total number of hours of lecture in an equivalent course in the US. Typically, there will be 60-70 hours of lecture per semester for an engineering course at UESTC. Attendance at lectures is mandatory in all classes for freshman and sophomores. The attendance policy is relaxed in the junior year.

Lecture notes may be posted on the electronic learning management system, which is Blackboard at UESTC. Typically, the lectures cover the same material as is in the textbook and topics not presented during lectures will not be included on exams. Students may follow the lectures using the textbook during class, but note taking is not routinely done. Even less common is a student who is willing to interrupt a lecture to ask a question or request clarification, if this is allowed by the course instructor. Students will wait until the end of the class period to discuss these issues with the course instructor, go to the instructor's office hours, or contact the graduate teaching assistant for assistance.

Laboratory courses are stand-alone courses with limited to no coordination between the instructors of the laboratory courses and the lecture course in which the abstract concepts are taught. Similar to the UK laboratory exercises, the labs are very proscribed. Opportunities to demonstrate creativity in design are left for extracurricular design competitions and projects 
constructed in Innovation Centers. However, participation in the competitions and access to the Innovation Centers is limited to students with excellent grade point averages.

\section{Descriptive and Proscribed Assessment of Student Learning $\subset$ Assessment Technique Selected by Instructor $\supset$ Proscribed Assessment}

\section{(a) University of Glasgow}

The contribution of the summative assessments for homework assignments, quizzes, and/or class exams - and a majority of the courses do not include such assessments - towards the final grade in courses is minor. The final exam generally contributes $70-90 \%$ to the final grade in each course with the assessment of the students' practical skills assessed during laboratory exercises and/or projects contributing the bulk of the remaining portion of the final course grade.

Grading of the laboratory exercises is, in large part, carried out by reviewing students' laboratory notebooks. Thus, the grades reflect not only the inclusion of correct results from analyses, simulations, and measurements, but also appropriate and timely record of observations and conclusions.

Questions on the final exams are expected to have proscriptive components with grades given for proper selection of analytical techniques and correctness of the solution. However, a considerable fraction of the questions are supposed to require the students to reflect upon their learning and describe their understanding of concepts to explain a specific result of a calculation or experiment, describe an application of a concept, or to develop conjecture about an extrapolation from the known. As each exam is moderated, as described in Section VI, there is a process in place to ensure that all exams contain both types of responses from students.

Conditions during exams are designed to limit the potential for student misconduct - students are not allowed to have anything other than the materials needed for the exam at their desks and desks are separated by approximately a meter in all directions. Invigilators (proctors) are hired and trained by the Registrar. The invigilators may be university employees or postgraduates from anywhere on campus or may even be people from outside of the university hired temporarily for the sole purpose of monitoring students during the exam week. Course instructors are asked to be available to answer questions about the exam questions, but are not present in the room during the exam. Any suspected incidence of student misconduct is reported by the invigilator to the Registrar. The report is then submitted to the Student Conduct Committee of the University Senate. The process from this point is similar to procedures used by the undergraduate Honors Courts at the US IHLS.

The course instructor is responsible for grading the exams; post-graduates may be employed to assist with grading of tutorial worksheets, quizzes, and lab reports. If a post-graduate assists with the grading of the final exam, there is supposed to be training and oversight provided to the student. The time between the exam and the date at which the instructor must have the final grades prepared is long, usually more than a month. Hence, there is sufficient time to grade short answer and essays on the final exams and project reports as compared to the 48 hour turn- 
around between the final exam and submission of grades expected, though not always achieved, at the IHLS in the US.

\section{(b) University of Electronic Science and Technology of China}

Summative assessments in a lecture course at UESTC include regularly assigned homework, project reports, a mid-term exam, which are usually held outside of normal lecture hours, and a final exam. The questions on the mid-term exams and final exams are proscriptive. Equation sheets are not regularly distributed as part of the exams. Thus, students must be able to remember the equations from the lectures, to select the appropriate ones; and to apply them correctly. Grades are usually determine by the correctness of the answer with little considerable given to the decisions that a student must make to select the appropriate equation to solve the problem as students are expected to know which equation that they have memorized should be applied.

Conditions during exams at UESTC are similar to that used at UoG. Students are not allowed to have anything other than the materials needed for the exam at their desks and they are seated as far apart as possible, given the design of the classroom. University staff are hired and trained by the Teaching Office to proctor the exams. Course instructors are asked to be present to answer questions about the exam questions. Any suspected incidence of student misconduct is reported by the proctor to the Teaching Office. Similar procedures are in place to handle such reports as are in place at UoG.

The course instructor, possibly with the support of graduate teaching assistants, grades the final exams and calculates the final grades in the course. The time between the last final exam period and the deadline to upload course grades is at least one week, though the time between the schedule of resit exams and the upload of the revised grades can be much shorter. As in the US, the course instructor usually has the authority to curve grades when calculating the final grades in a course. The weight of the final exam towards the course grade is much less, $30-40 \%$. The weight of the mid-term is usually $20 \%$ with the remainder distributed between the contributions for homework assignments, projects, and class attendance.

\section{Accreditation by IET $\cong A B E T \sim C A S T / C E E A A$}

\section{(a) University of Glasgow}

The Institute of Engineering and Technology (IET), as a member of the Engineering Accreditation Board, conducts the review of the UoG EEE program, as licensed by the Engineering Council. Full Chartered Engineer (CEng) and Incorporated Engineer (IEng) accreditation of an engineering degree is awarded at the Masters level, rather than undergraduate degrees as done in the United States. Partial accreditation may be awarded by the IET to undergraduate engineering programmes. The UoG EEE programme has been fully accredited through August 31, 2014 ${ }^{9}$. The IET has recently completed the review and it is expected that the EEE programme will receive full accreditation, which will be valid through 2019, the maximum five-year period. 
Accreditation process by the IET follows a similar format to that used by ABET in the United States ${ }^{10}$. A report that documents the means by which the programme enables students to meet the general and specific learning outcomes, criteria established by the Engineering Accreditation Board ${ }^{11}$. This includes general information from the programme specification, a report by the external examiner, a brief statement on the programme learning outcomes as they relate to the four UK-SPEC General Learning Outcomes (knowledge, intellectual abilities, practical skills, and general transferable skills), a report on the programme quality assurance structure and procedures, the staff, resources, and future plans. The second section of report includes examples of student work from the past three years (excellent, good, fair, poor but sufficient, and insufficient quality), input obtained on the programme from industry, admission and graduation criteria and percentages, and other details related to study-abroad partnerships and professional activities available to students. Lastly, the report must include a matrix that shows how the programme meets the general, specific, Masters programme, and MSc learning outcomes, as appropriate for the accreditation application. Visits by a panel of trained expert accreditors are also conducted as part of the accreditation process. The panel makes a recommendation to the Academic Accreditation Committee of the IET, which then decides whether the programme should receive accreditation.

\section{(b) University of Electronic Science and Technology of China}

Hong Kong China is a signatory to the Washington Accord ${ }^{12}$. However, this status does not extend to China as a whole, which current holds provisional status ${ }^{13}$. The China Association for Science and Technology (CAST) is the organization representing the nation as it develops the accreditation procedures ${ }^{14}$. According to a news article posted on the CAST website, China has submitted a formal application in 2014 to become a signatory of the Washington Accord in $2015^{15}$. When China becomes a signatory of the accord, CAST or an organization authorized by CAST will accredit engineering programs in mainland China. China Engineering Education Accreditation Association (CEEAA) is the organization authorized to accredit engineering programmes, according to its website ${ }^{16}$.

Until such time as China became a signatory of the Washington Accord, a program may be accredited by an authorized organization of one of signatories on the accord. The IET has already reviewed the engineering programs offered by Queen Mary University of London-Beijing University of Posts and Telecommunications ${ }^{17}$ and Is currently conducting a review of at least one more Sino-UK joint educational programs in China this year ${ }^{18}$. ABET has accredited a chemical engineering program offered by East China University of Science and Technology, but has not accredited any of the Sino-US undergraduate engineering joint programs as of yet ${ }^{19}$, although several such programs do exist. Accreditations by IET and ABET of programs in China may continue after the approval of China as a signatory on the Washington Accord.

The general criteria and fourteen engineering complementary program criteria that will be used to assess programs by CEEAA ${ }^{20,21}$ are similar to the current ABET general and program criteria ${ }^{22}$. There are several differences, however. General criterion 1.5 Curriculum is reminiscent of the pre-ABET 2000 criterion as it contains a list of specific aspects of student training and the required percentages of the total credits in a program that must be dedicated each - natural sciences and mathematics (> $15 \%$ ), engineering fundamentals (30\%), engineering practice and a final-year 
design (20\%), liberal arts (> $15 \%$ ). Engineering practice and design must involve people from outside of the academic program, "experts from industry or enterprises" 20 . The criterion on faculty states that there must be some part-time faculty associated with the program who are employed by either organization.

\section{Quality Assurance $\approx$ Continuous Improvement $\rightarrow$ Continuous Improvement}

\section{(a) University of Glasgow}

Universities in the United Kingdom have integrated quality assurance procedures into their academic schedule to insure that the summative assessments in each course address the set of intended learning outcomes, students are assessed fairly and in the same depth in each course from offering to course offering, the progress of each student is reviewed throughout his or her academic career, and lastly to insure that the programme aims and learning outcomes are achieved. Thus, the quality assurance procedures are approximately equivalent to the process of continuous improvement that each ABET-accredited program is expected to develop.

As mentioned, there is a significant amount of sharing of materials by the course instructors, initiated by the course convener. Hence, the variability in the learning materials available to students from one semester to another is smaller than that which the author was accustom when teaching at the three IHLs in the United States. However, the choice of the material presented during lecture and the emphasis placed on each topic is left to the course instructor.

To insure that the intended learning outcomes of the course are assessed, the final exam in each course is moderated. Moderation is a process in which another staff member, usually the course convener if he or she is not also the course instructor, reviewed the proposed final exam, the marks (points) associated with each exam question, and the solution to each question. The internal exam moderator provides feedback on the exam questions with suggested rewording of question statements improve clarity; requests for change in question style, for example rephrasing of a question from a proscriptive form to descriptive; and required alter questions or add/subtract ones so that specific intended learning outcomes are assessed. Once the internal exam moderator and course instructor have reached an agreement, the exam is then reviewed by an external examiner. An external examiner is a paid consultant, typically current or recently retired professor from a peer institution, who has been hired to provide an independent assessment of the degree programme. Once the external review has been completed with appropriate changes made to the exam, the exam can then be given to the students in the course. As each exam is made publically available on the UoG library website, new exams are written each time a course is taught and another round of exam moderations is conducted. This process is coordinated by administrative staff in the UoG School of Engineering Teaching Office (an organization whose responsibilities include aspects of student advising and academic affairs).

An Exam Board is held at the end of each semester before the final grades in a course can be released. The board is composed of all of the academic staff who taught courses in a particular programme; the programme director, the quality assurance manager for the academic organisation, members of the Teaching Office, the chair of the board, and on occasion the 
external examiner. Each staff member presents the raw final grades for all of the students in the course, i.e., no curving or rounding of individual scores is permitted. Prior to this, another staff member has reviewed the grades to verify that the marks have been assessed in a similar manner to the way that they were assessed in previous semesters and that the final scores on the exams were calculated properly. The course instructor also provides his or her opinion on the administration of the course and suggestions on what steps may be done to normalize the grades on individual components and/or the final grades in the course with respect to the average and mean of the final grades given in previous semesters. The Teaching Office supplies the statistics about the past and current final course grades. Following a discussion, the attendees vote upon any suggested steps to alter grades in a particular course, identified by either the course instructor or by one of the board attendees during the discussion. If such steps are agreed upon, the course instructor recalculates the final grades; otherwise, the initial raw grades are used as the final grades in the course. Once the grades in all courses in the programme that were taught in that semester have been reviewed, the programme director collects input from the attendees on programme specification. The remarks from the external examiner are weighted very heavily when changes to the programme are then considered.

Similarly, exam moderation is done for the exams taken by students who must resit a final exam in order to pass a course. Resit Boards are held to review the results of the grades that students who have resubmitted work that contributes to the recalculation of their final grade in the course, including the resit of the final exam.

Once the Resit Boards have met, the progression rules are applied to determine which students have made adequate academic progress and will be allowed to enrol in the courses for the next year of the programme. These students may include some who failed to achieve satisfactory grades, i.e., a grade of less than a D3 (D-), in one or more courses. In such a case, the student is required to resit some or all assessed components of the course(s) in which he or she has received failing grades before the completion of the next academic year. Failure to pass the course(s) after the second resit opportunity could result in the student being dismissed from the programme, following a review of the student's academic performance by the Progress Board. Students who failed to achieve satisfactory grades in multiple courses or extremely unsatisfactory courses in at least one course, i.e., less than an E3 (a low F) will be asked to sit out a year and resit the final exams in the courses that they have failed at the end of that year. If a student's performance is particularly poor, especially if there is evidence that the student has not participated in the laboratory exercises, as indicated by a grade of credit withheld; or if there are any significant irregularities that have resulted in credit being refused in one or more courses, the Progress Committee may decide that the student should be dismissed from the programme.

At the completion of the Year 4 courses, a Graduation Committee is convened to review the academic performance of all students who are eligible to graduate. The Graduation Committee will determine which students are eligible to graduate with an honours degree and which may graduate with an ordinary Bachelor's of Engineering. Students may not resit the Individual Project or assessed components of the Year 4 technical elective courses and graduate with an honours degree. A student may elect to resubmit the final report for the project if his or her performance on the project was unsatisfactory in order to obtain an ordinary degree. If the student's overall performance in Years 3 and 4 is of sufficient quality, a student may be allowed to graduate with 
an ordinary degree without a resit of the technical elective courses that he or she did not pass. Note that the Progress Committee may have already determined that a student is not eligible for an honours degree based upon his or her academic performance during Year 3. The Graduation Committee also has the responsibility to verify that the intended learning outcomes for the programme have been achieved by every graduating student.

A student has the right to appeal all decisions made by the Exam Board, Resit Board, Progress Committee, and Graduation Committee as well as the grading of the assessed materials that he or she has submitted. The processes for such appeals are documented in the University Calendar (a combination of student and faculty handbook.

An annual report on the programme is written by the programme director, reviewed by the academic division's quality officer, and then submitted to the University Senate. The report includes a summary of actions suggested by the external examiner who makes recommendations in his or her annual review of the programme as well as actions suggested by the staff involved in the programme and the School of Engineering Teaching and Learning Committee and its Teaching Office and a list of proposed steps that will be taken to address these suggestions.

\section{(b) University of Electronic Science and Technology of China}

A similar process for student progression is used at UESTC. The Student Academic Affairs office associated with each degree program is responsible for monitoring students' progress towards their degree. Students at UESTC are permitted to resit mid-term exams and final exams, should they not receive a satisfactory grade in a course, i.e., a final grade of less than $60 \%$ (an F). These resit exams are scheduled during the first two weeks of the following semester. If a student does not achieve a passing grade in the course after the first resit, the student must retake the course. Depending on the number of courses that a student has not passed, the student may enroll in more advanced courses, assuming that the courses in which the student failed are not prerequisites for the advanced courses. However, the Academic Affairs Office may suggest that the student concentrate on the courses that he or she is retaking, rather than enrolling in these and additional courses. Nevertheless, the decision on the number of courses to retake and when they should be retake as well as enrollment in additional advanced courses is the student's.

Since program accreditation is relatively new, most of the engineering degree programmes at UESTC are not accredited. Hence, procedures to measure student achievement of program educational objectives are in the early stages of development and refinement by a couple of Schools at UESTC that oversee programs have been accredited by or are about to be reviewed by CEEAA. Thus, staff in most Schools at UESTC are unaware of the process of program evaluation through quality assurance or continue improvement with the accompanying analysis from data collected from multiple inputs and constituencies. An administrator from the UESTC School of Communication Information and Technology, which will host a visit by a CEEAA accreditation team in the near future, explained that the data analysis that must be used in the continuous improvement process expected by CEEAA is much more quantitative than the analysis of data either currently carried out in the quality assurance process in place at UoG or that was employed to support the continuous improvements processes used in the departments at the US institutions with which the author is familiar. Thus, the author cannot provide a more detailed description on continuous improvement expected by CEEAA. 


\section{Students' Rights $\supseteq$ Students' Rights $\not \subset$ Students' and Parents' Rights}

\section{(a) University of Glasgow}

Students' rights and influence on academic affairs are at least as strong at the University of Glasgow as they are at any of the three institutions of higher learning in the United States. As is true in the United States, academic and administrative staff are not allowed to disclose any information about a students' performance at the University of Glasgow without the express permission of the student. The argument sometimes put forth in the United States - that parents has the right to know their child's grades in college because they are footing the bills - is less valid for home students (residents of Scotland) or non-UK European Union students as the Student Awards Agency for Scotland will pay the tuition at a Scottish university as long as the student is making adequate progress towards a degree. [The student, or his or her parents, must still pay the other fees assessed by the university, which can be substantial but nowhere close to the tuition, upwards of $£ 9,000$, charged by public universities in England or the tuition and fees at most universities in the US.]

Other rights are documented in the University Calendar and posted publically on the Registrar's website, which is easily searchable from the University's home page. The UoG Student Union actively monitors the University's compliance with its own policies, campaigns for modifications to existing policies and institution of new policies, and provides advice to students who are considering the submission of appeals to the University on decisions by the Exam and Resit Boards and Progress and Graduation Committees as well as grades on assessed course materials.

Input from students is solicited on new programmes as a required component of the University approval process. A student focus group must be convened to obtain student opinion on the viability of the programme with respect to student interest in enrolment in such a programme and potential employment opportunities of graduates from the programme. Comments from the focus group help shape the programme structure and aims. Also, a student representative is a member of the School of Engineering' Teaching and Learning Committee and who has a vote on the approval of the programme and any modifications to the programme specifications and the associated course specifications.

Once a programme has been launched, student-staff liaison committee meetings are held at least once a semester to allow students an opportunity to voice concerns about course content and instruction in the programme. Issues raised during the committee meetings are discussed with the programme director, the head of discipline, and with the members of the School of Engineering management committee, which is chaired by the head of the School. Prompt response to the issues, if only to state that the issues have been heard though a plan for action is preferred, is expected.

A national student survey (NSS) is conducted annually in the United Kingdom to measure student satisfaction with the quality of the learning experience in the programme of study. Student responses are compiled and compared with responses from other students enroled in similar programmes through the UK. Scores, correlated with particular programmes of study, are 
publically released, which can trigger an immediate review of the programme, should the University administration consider the NSS score to be too low.

\section{(b) University of Electronic Science and Technology of China}

There are numerous interactions between academic and administrative staff with parents at UESTC as compared to that at either UoG or the three IHL in the US. Many of the students' parents are actively engaged with UESTC while their children are students at the institution. The parents create email listservs and launch QQ accounts (similar to Twitter) where conversations about student life and the quality of instruction are regularly posted. UESTC administrative staff monitor these conversations daily and are expected to promptly respond to questions and address issues with other members of staff in the programme. A parents' liaison committee meets at least once a semester with the leadership of the programme to discuss improvements to the programme, the extracurricular activities available to students, and other issues of interest to the parents.

A student can use the communication path established between parents and university administration to get his or her own concerns about a program, course, or instructor addressed quickly by posting comments on a class QQ account, which is monitored by both parents and UESTC staff. If a response to the comment from UESTC is slow to appear, parents may pick up the issue and discuss it on the parents' listserv and/or QQ account, which have greater impact.

Discussions of student performance with parents are conducted with and without the knowledge and consent of the student involved. As UESTC employs staff to coordinate extracurricular activities in the evenings and on weekends and monitors student participation in these activities, staff are expected to provide detailed information to the parents on daily life of a particular student from the moment the student wakes up to the time that he or she goes to sleep every day of the week. Furthermore, parents expect to be contacted as soon as the academic performance of their child begins to decline and/or their level of engagement in extracurricular activities is not high. Face-to-face meetings between parents and UESTC staff may even be scheduled to hold such conversations.

Privacy of student data, particularly grades, is not a concern. Class representatives, initially selected by UESTC and later elected by classmates, collect ungraded materials from their fellow students and return the graded copies to each student. No effort is made by the course instructor to hide the grades on the assignment or exam. Furthermore, administrative staff will contact the class representative for assistance in tracking down a student who fails to submit an assignment or attend a required class and will solicit the class representative's opinion about the student and the cause of the poor academic performance.

\section{UoG $\cup$ UESTC $=$ The UoG-UESTC Joint School}

\section{(a) Educational Programme}

The original UoG-UESTC programme specification was composed of a selection of UoG courses, taught by UoG staff, and UESTC courses taught by UESTC staff. The sum of the material covered 
in all of the courses met the aims of the programmes offered at each of the institutions. This enabled rapid approval of the programme by the Learning and Teaching committees in UoG School of Engineering and the College of Science and Engineering and by the UoG Senate, a necessity as the students who graduate from the joint educational programme will receive Bachelor degrees from UoG as well as from UESTC. A major deviation from the UoG EEE programme specification was the inclusion of UESTC courses on basic science and mathematics. There was duplication of topics covered in some of the UoG and UESTC courses to ensure that students learned the material that was not covered in one or the other course. The duplication proven to be problematic. Students did not appreciate the duplication of lectures or assessments and they found it difficult to manage the extra workload created by the duplication. Furthermore, timetabling the larger than normal number of required courses per semester, partially caused by the duplication, was extremely difficult. Revisions to some of these courses are now underway to include material from a UESTC-taught course in a UoG-taught course and vice versa to eliminate the duplication of material and reduce the courses and the number of credits required for graduation. In addition, a subset of the liberal arts courses required by UESTC, specifically four English courses, have been added to the programme specification to demonstrate to students that both institutions place a high value on these courses, especially as all the courses listed in the programme specifications are taught in English. The only change to the programme specification that met with significant resistance has been the addition of the English courses. Several meetings were held at UoG including a number with members of the UoG Senate before seeking approval of the revisions to the UoG-UESTC programme specification as some of the UoG community considered the addition to greatly alter the character of a programme in which a UoG engineering degree would be awarded.

\section{(b) Learning Styles}

One of the many goals of the collaboration between UoG and UESTC is to create a merged pedagogical approach that takes the best techniques used by both institutions to instill a deep understanding of theory and to promote creativity in design ${ }^{23}$. To succeed, one must fairly evaluate the instructional techniques used at the two institutions as well as consider the current and desired learning styles of the students.

The process of evaluation has been slow, in part because much of the time when UoG staff are at the UESTC campus is devoted to course delivery and the Joint School staff meetings have been focused on informing the staff about the policies that are unique to Joint School. Thus, a consensus on the characteristics of the 'desired' learning style has yet to be reached. As a result, the learning style expected of the students, and hence the instructional techniques applied to foster that particular style, has swung between teacher-centered to self-directed learning, depending on whether the course was taught by a UESTC or UoG staff member. As most of the courses in the first two years of the programme are taught by UESTC staff, the staff at the Joint School has found that most of the UoG-UESTC students are having difficulties adopting the learning style needed to succeed in the UoG-taught courses.

As the most critical issue in the Joint School is to support the learning by the students, the UoGtaught courses in Year 1 are being restructured to include an assessed class exam (mid-term) to introduce the UoG-UESTC students to descriptive style of exam questions before they take the 
final exam. The contribution of the class and final exams to the final grade in the Year 1 UoGtaught courses have been reduced; less than the original weight, but still larger than the typical weight of the mid-term and final exams in the Year 1 UESTC-taught courses. The inclusion of graded homework in the calculation of the final grade in the Year 1 UoG-taught courses is also under consideration. Thus, the number and weight of the assessments in the Year 1 UoG-taught courses will be a step between the UESTC-taught courses and the Year 2 UoG-taught courses. Furthermore, the UoG staff have been asked to provide more guidance on the material that students should study for the class and final exams. The staff at UESTC have combined the lecture course on digital logic with the companion lab course and the lecture course on analog circuits with its companion lab course so that the electronics engineering courses taught by UESTC staff have a similar overall structure to the courses taught by UoG staff.

Both institutions are actively working to insure that students are prepared for open-ended design projects and to foster creativity in design. $50 \%$ of the laboratory exercises in half of the Year 1 and Year 2 UoG-taught courses have been replaced with team and individual design projects. UESTC staff are strongly encouraging all UoG-UESTC students to participate in extracurricular design competitions from the beginning of their academic studies. Projects have been introduced in the UESTC-taught course in linear algebra and space geometry and the UESTCtaught course on numerical methods and MATLAB.

Prior to the opening of the Joint School, the staff at UoG recognised that all UoG-taught courses should have required textbooks to support the development of self-directed learning as well as to assist the UoG-UESTC students as they build their technical English vocabulary. The required textbooks were a subset of the books that the UoG staff recommended to the UoG students written in the style that is generally accepted by UK educators and authored almost entirely by experts who are from Europe or North America, and published by companies with headquarters in the same countries. Unfortunately, neither the UoG nor UESTC staff realized the challenges involved in purchasing these textbooks. First, there is no bookstore on the UESTC campus or in the neighboring community so students must order the books online. A further complication is that there is limited availability of English-language engineering textbooks in China. Not all of the textbooks that were identified by UoG staff are sold in China and it can take months for a bookseller to import a large number of copies of the English-language textbooks that are sold in China, once stock on hand has been sold. The cost of the textbooks are considerably more expensive than equivalent textbooks written in Chinese, although comparable in price to the same textbooks purchased in the UK. Thus, students tend to purchase the equivalent Chineselanguage textbooks. UoG staff will contact book publishers to determine which have developed relationships with book importers in China and/or have established a means to print books directly in China to then determine which textbooks should be required for UoG-taught courses.

\section{(c) Assessment of Student Learning}

As mentioned, UoG-taught courses in Year 1 are undergoing a revision to assess student learning throughout the semester. This change has been enthusiastic endorsed by the UESTC administrators in the Joint School, several of whom have expressed reservations about the ability of young adults to engage in self-directed learning, particularly in the early stages of their undergraduate education. Efforts to inform UESTC staff on techniques to write assessments 
using descriptive questions have begun. Examples of exam questions have been distributed during staff meetings at the Joint School. UoG staff presently moderate all exams taken by students in the courses identified in the joint educational programme, independent of the institution responsible for the course instruction. The UoG moderators have been instructed to suggest changes on exam questions that would alter the style of question from proscriptive to descriptive and to provide examples of descriptive questions that could be used to probe the depth of student understanding on the same topic as the proscriptive question written by the UESTC staff member. There has been limited adoption of this style of exam question by the UESTC staff, which has been raised as a concern by the UoG external examiner. The effort to train UESTC staff on the use of descriptive questions in the assessment of student learning will continue for the foreseeable future. The number of UESTC staff involved in delivery of the UoG-UESTC courses will continue to increase for the next three years until student enrollment in the UoG-UESTCEEE program reaches its target. Training will be necessary in the following years as turnover of UESTC staff occurs.

\section{(d) Accreditation}

As part of the memorandum of agreement signed by the two institutions, UoG agreed to have the EEE programme accredited. What is not clear at the moment is which organization must UoG approach for accreditation. When the Joint School was launched, China did not hold provisional status on the Washington Accord. Thus, it was thought that UoG would request the IET to review the UoG-UESTC EEE programme. Given this, UESTC has initiated discussions with IET and IET staff have conducted workshops on accreditation at UESTC during the past year. The School of Electronic Engineering, which oversees the UESTC engineering program in which the UoG-UESTC students are enrolled, has signed a memorandum of understanding with IET with the intention that IET will conduct a review the degree programs offered through the School. However, China has applied for formal membership in the Washington Accord with the intent of joining some time in 2015. Hence, the programmes offered by the School of Electronic Engineering may have to be accredited by CEEAA in the near future. A further complication is that there is some uncertainty within UoG as the interpretation of the third point in the Washington Accord ${ }^{12}$. It is not clear whether it is the location of the institution of higher learning that is awarding a degree or the location of where the students who are enrolled in the programme are taught that defines the national boundaries, which will then determine if IET or CEEAA must accredit the UoG-UESTC programme.

Given that the EEE programme offered in the UK is accredited by IET and the Electronic and Electrical Engineering programme offered by the UESTC School of Electronic Engineering will likely have to be accredited by CEEAA in the future, UoG staff who teach at the UoG-UESTC Joint School and participate in some teaching activities at the UoG Gilmorehill campus in the UK should be aware of the criteria and accreditation procedures used by both organizations. Thus, the program aims and the courses that support the student attainment of the UoG-UESTC EEE programme aims will be mapped to the criteria used by IET and by CEEAA. The newness of the CEEAA accreditation process with the brief description of the accreditation procedure available in English on the organization's website coupled with the limited experience at UESTC with accreditation in general currently present a tremendous challenge, should a CEEAA accreditation 
of the UoG-UESTC programme be required to satisfy this aspect of the memorandum of agreement.

\section{(e) Quality Assurance}

Since the initial assumption on programme accreditation was that IET would be asked to review the UOG-UESTC EEE programme, the UoG procedures for quality assurance have been followed since the UoG-UESTC Joint School opened. The differences in institutional personalities of the two universities became very apparent as these procedures were introduced. UoG is very structured in terms of its administrative policies and procedures. Deadlines for submission of course and programme modifications and the associated committee meetings for the reviews, for example, are fixed and determined more than a year in advance. Responses to events covered by existing university policies are formalized and deviations must be reviewed by upper administration and/or the University Senate. Planning at UESTC tends to be focused on nearterm deadlines. For example, dates for major student recruitment events and submission of a proposal have been mentioned to UoG staff with two weeks' notice with the expectation that the UoG staff will be able to contribute the resources needed to make the event or proposal successful. Unfortunately, this has not always been possible, given the UoG approval process. There have also been misunderstandings about what is a rule as opposed to a guideline at UESTC as UESTC appears to allow more flexibility in the application of university policies than is allowable at UoG. Overall, the near-term focus of UESTC has meant that most of the UoG academic and administrative deadlines have been followed.

\section{(f) Other Issues}

There remains a number of complex issues, such as students' right to privacy, that require negotiations between the two institutions to find a compromise between existing policies and procedures. Such negotiations address the differences in background and expectations of students, staff, parents, and other constituents including employers of the graduates from the programme and the institutions of higher education at which our graduates attend for postgraduate education. A critical step that must be taken before each issue is discussed is the exchange of policies and guidelines as well as a conversation on the expectations of student, staff, and other constituents at each institutions to limit misunderstandings and overcome preconceptions.

Efforts to develop a shared vision of the learning style that students should develop while studying at the Joint School and an agreement on how to merge pedagogical approaches to achieve the desired depth of understanding and creativity in design will continue. Discussions about the impact of the programme revisions as the changes are introduced, supported with an assessment that the changes have had on student success in individual courses and the achievement of the programme aims, will contribute significantly to these efforts.

\section{Acknowledgements:}

The author would like to acknowledge the assistance that she has received from her colleagues at the University of Glasgow and in particular Prof. John Marsh, Head of the School of Engineering 
(SoE); Prof. John Davies, SoE Transnational Education Coordinator and CoSE Dean of Teaching and Learning; Prof. Scott Roy, Head of the EEE Discipline; Ms. Laura Dickson, Mr. Jared Philippi, and Ms. Katy Phillips, SoE External Relations; Dr. Karen Mcllvaney, Sr. Administrator of the SoE Teaching Office; Ms. Emma O'Donnell, SoE TNE Teaching Support; Ms.Ruoli Zhong, UoG-UESTC Administration Manager; and Dr. Shengrong Bu, Dr. Keliang Zhou, and Mr. Duncan Bremner. She would also like to acknowledge the assistance that she has received from her colleagues at the University of Electronic Science and Technology of China and in particular Dr. Zhiqin Zhao, Dean of the UoG-UESTC Joint School; Dr. Xingang Liu, Vice Dean of Academic Affairs; Mr. Michael Gao, Vice Dean and Party Secretary; Ms. Fengwu Luo, Director, Academic Affairs Office; and Dr. Lili Ma, Laboratory Manager.

\section{References:}

${ }^{1}$ The Global Times, Stricter Scrutiny for Sino-Foreign Joint Education, September 3, 2013. http://www.globaltimes.cn/content/808914.shtml\#.UvOfu_I_uXw. [Online: Viewed February 6, 2014.]

2 Y. Sharma, China to Evaluate Foreign University Presence and Prepare Guidelines, University World News, No. 205, Jan. 22, 2012, http://www.universityworldnews.com/article.php?story=20120118202525930 [Online: Viewed Dec. 27, 2014].

${ }^{3}$ Y. Sharma, Branch Campus Growth Has Moved to Asia, No. 204, Jan. 13, 2012, University World News [Online: Viewed Dec. 27, 2014].

${ }^{4}$ University of Glasgow, Glasgow launches joint engineering programme with UESTC, China, May 2013. http://www.gla.ac.uk/news/archiveofnews/2013/may/headline_277570_e n.html [Online: Viewed February 6, 2014.]

${ }^{5}$ BEng Electronics and Electrical Engineering, http://www.gla.ac.uk/t4/progspecs/files/2014/BEng Electronics and Electical Engineering $\mathrm{H}$ H56-2200.pdf [Online: Viewed Dec. 26, 2014].

${ }^{6}$ ABET Engineering Accreditation Commission, Criteria for Accrediting Engineering Programs, Nov. 1, 2014, http://www.abet.org/eac-criteria-2015-2016/ [Online: Viewed Dec. 26, 2014].

${ }^{7}$ University of Electronic Science and Technology of China Course Catalogue, published in 2012.

${ }^{8}$ The Moodle Project, https://moodle.org/ [Online: Viewed Mar. 15, 2015].

${ }^{9}$ Institute of Engineering and Technology, Academic Accreditation: List of IET Accredited Programmes, http://www.theiet.org/academics/accreditation/downloads/accreditedprogs.cfm?type=pdf [Online: Viewed on Dec. 27, 2014].

10 The Institute of Engineering and Technology, The Process for Academic Accreditation, http://www.theiet.org/academics/accreditation/process/ [Online: Viewed Dec. 27, 2014].

${ }^{11}$ Engineering Accreditation Board, Documentation, http://www.engab.org.uk/documentation\#EAB Full Submission For BSc, BEng and MEng Programmes [Online: Viewed Dec. 27, 2014]. 
${ }^{12}$ International Engineering Alliance: Educational Accords, Accords Rules and Procedures, June 13, 2014, http://www.ieagreements.org/Rules and Procedures.pdf?3437 [Online: Viewed Dec. 26, 2014].

${ }^{13}$ International Engineering Alliance: Washington Accord Signatories, http://www.ieagreements.org/Washington-Accord/signatories.cfm [ Online: Viewed Dec. 26, 2014].

${ }^{14}$ China Association for Science and Technology, Reform of China's Engineer System and China's Engineering Program Accreditation, http://english.cast.org.cn/n1181872/n1182065/n1182088/46506.html [Online: Viewed Dec. 26, 2014]/

${ }^{15}$ China Association for Science and Technology, Shang Yong Meets with Washington Accord Review Team, http://english.cast.org.cn/n1181872/n1182018/n1182077/16048786.html [Online: Viewed Mar. 15, 2015].

${ }^{16}$ China Engineering Education Accreditation Association, Introduction, http://www.ceeaa.org.cn/index.html, [Online: Viewed Mar. 15, 2015].

${ }^{17}$ Top Professional Engineering Body Endorses QMUL's Joint Programme in China; June 26, 2014, http://www.qmul.ac.uk/media/news/items/se/134267.html [Online: Viewed Dec. 27, 2014].

18 Private communication

${ }^{19} \mathrm{ABET}$, Find an Accredited Program: China, http://main.abet.org/aps/AccreditedProgramsDetails.aspx?OrganizationID=9565, [Online: Viewed Dec. 27, 2014].

${ }^{20}$ China Engineering Education Accreditation Association, General Criteria, http://www.ceeaa.org.cn/criteriaG en.html, [Online: Viewed Mar. 15, 2015].

${ }^{21}$ China Engineering Education Accreditation Association, Complementary Program Criteria, http://www.ceeaa.org.cn/ [Online: Viewed Dec. 27, 2014].

${ }^{22} \mathrm{~J}$. Yi and Y. Fan, The Revelation of Washington Accord to Chinese Engineering Education, 2014 International Conference on Advanced Education and Management, Beijing China, Jan. 4-5, 2014, p. 244-249.

${ }^{23}$ K. Meehan, J.H. Davies, S. Roy, J.H. Marsh, Y. Li, S. Gao, D. Zhou, Z. Zhao, X. Liu, and F. Luo, Merging Pedagogical Approaches: University of Glasgow-UESTC Joint Education Programme in Electronics and Electrical Engineering, IEEE Frontiers in Education, Oct. 23-25, 2014. 